Boota Singh ${ }^{1}$, Rohan Ranjan Waliya ${ }^{1}$ Sougata Santra ${ }^{2}$, G. V. Zyryanov ${ }^{2,3}$, Kousik Giri ${ }^{{ }^{1}}$

${ }^{1}$ Department of Computational Sciences, Central University of Punjab, Bathinda, Punjab, India ${ }^{2}$ Department of Organic and Biomolecular Chemistry, Chemical Engineering Institute, Ural Federal University, 19 Mira St., Ekaterinburg, 620002, Russian Federation ${ }^{3}$ I. Ya. Postovskiy Institute of Organic Synthesis, Ural Branch of the Russian Academy of Sciences, 22 S. Kovalevskoy St., Ekaterinburg, 620219, Russian Federation ${ }^{\star}$ E-mail: kousikgiri@gmail.com

\title{
Effect of Alkylation on the Kinetic Stability of Arsenodiester and Organoarsenicals against Hydrolysis: A Theoretical Study
}

Arsenic diesters have same structural and chemical properties as $P_{i}$ (phosphate) diester. Beside this structural similarity, arsenate is not considered by cellular processes to replace phosphate. Quantum calculation reveals that this happens due to very high hydrolysis rate of $\mathrm{As}_{\mathrm{i}}$ diester (As-0-bond-based compounds) as compared to $\mathrm{P}_{\mathrm{i}}$, but how organoarsenicals (As-C-bond-based compounds) that are produced by alkylation of $\mathrm{As}_{i}$ survive in highly aqueous tissues of marine organisms? We found that this alkylation results in lower hydrolysis rate of As diester. Our work concluded that alkylating effort by our body on $\mathrm{As}_{\mathrm{i}}$ is to avoid structural ambiguity with phosphate and excrete out arsenic in the form of organoarsenicals from body.

Keywords: arsenic, arsenobetaine, arsenocholine, arsenosugar, DMA, MMA, arsenate organoarsenicals, arsonic acid, hydrolysis

Received: 14.06.2018. Accepted: 27.07.2018. Published: 30.07.2018.

(c) Boota Singh, Rohan Ranjan Waliya, Sougata Santra, Zyryanov G. V., Kousik Giri, 2018

\section{Introduction}

Arsenic (As) is one position below phosphorus $(\mathrm{P})$ in the same group of the periodic table, that is why it shares the fundamental chemical properties with phosphorus. In the environment arsenic exists in four oxidation states: $-3,0,3$, and 5, while the elemental arsenic occurs rarely [1]. Arsenite [As (III)] is the most toxic form of inorganic arsenic, mainly found in anoxic environments, whereas less toxic arsenate $[\mathrm{As}(\mathrm{V})]$ occurs in aqueous, aerobic environments [1]. Due to structural similarities of arsenate and phosphate, phosphate transporters cannot easily distinguish between $\mathrm{As}_{\mathrm{i}}$ and $\mathrm{P}_{\mathrm{i}}$, which results in the substitution of $A s_{i}$ in many $\mathrm{P}_{\mathrm{i}}$-based metabolic pathways (Table 1) [2]. However, $\mathrm{As}_{\mathrm{i}}$-based compounds are hydrolysed much 
Table 1

Evidence of arsenate substitution for phosphate in biochemical processes

\begin{tabular}{|c|c|c|c|}
\hline Reaction or enzyme & Arseno-analogue & Phosphate compound & Reference \\
\hline Adenylate deaminase & 5'AMAs & 5’AMP & {$[6]$} \\
\hline Adenylate kinase & 5’AM (CH2) As & AMP & [7] \\
\hline Chloroplastic electron transport & ADP-As & ATP & {$[8]$} \\
\hline $\begin{array}{c}\text { Glucose-6-phosphate } \\
\text { dehydrogenase }\end{array}$ & Glucose-6-arsenate & Glucose-6-phosphate & [9] \\
\hline Hexokinase & ADP-As & ATP & [9] \\
\hline $\begin{array}{l}\text { Human red blood cell sodium } \\
\text { pump }\end{array}$ & Asi & $\mathrm{Pi}$ & {$[2]$} \\
\hline Purine nucleoside phosphorylase & Asi & $\mathrm{Pi}$ & [10] \\
\hline
\end{tabular}

faster than phosphate compounds [3], but the kinetics of hydrolysis decreases by increasing size of alkyl substituent on arsenate due to steric effect [4]. Alkylation is also utilised by marine organisms to produce organoarsenical products from arsenate, like arsenobetaine $\left(\mathrm{Me}_{3} \mathrm{As}^{+} \mathrm{CH}_{2} \mathrm{COO}^{-}\right)$, arsenocholine $\left(\mathrm{Me}_{3} \mathrm{As}^{+} \mathrm{CH}_{2} \mathrm{CH}_{2} \mathrm{OH}\right)$ and arsenosugar [1]. Even different pathways, proposed for arsenic metabolism in mammals, also lead to methylated end product of $A s_{\mathrm{i}}$ [5]. A very high percentage (> 70\% of total arsenic) of these organoarsenicals is found in kidney and muscles of marine animals [1].

The quantum chemical calculations performed by Mlàdek et al. [11] reveals that neither steric hindrance nor polarity of the solvent is able to reduce the high hydrolysis rate of arsenate monoesters as compared to monoesters of phosphate. But Mlàdek et al. [11] performed the theoretical modelling on the kinetics of the arsenate-ester hydrolysis by using mono-alkyl-arsenates only, whereas arsenate in organisms occurs as diester forms. Chemically, diester has a very profound role in the kinetics of $\mathrm{As}_{\mathrm{i}}$ hydrolysis because of steric hindrance and electronic effect as compared to mono es- ter, where $\mathrm{As}_{\mathrm{i}}$ is enclosed by a single ester linkage. One interesting fact about protecting hydrolysis of $\mathrm{As}_{\mathrm{i}}$ is itself provided by organoarsenicals produced by marine organisms. These organic As compounds have a direct As-C bonding as compared to inorganic As, which have As-O bonding. Because As-C bond is less polar as compared to As-O bond due to lesser electronegativity of $\mathrm{C}$ than $\mathrm{O}$, this would leads to the decrease in the reactivity of nucleophilic water towards As-C-bond-based compounds. The process of converting AsO-bond-based compounds to As-C was also proposed in mammals, where liver cell first reducts As, diester by using glutathione and then, after methyl transferases for methylation, finally produced various species of arsenic acid from $\mathrm{As}_{\mathrm{i}}$ diester (see Fig. 1).

In this regard, a theoretical model based study is essential to compare the hydrolysis rate of alkylated $\mathrm{As}_{\mathrm{i}}$ diester with diester of $P_{i}$ and to understand the mechanism behind the alkylation of $\mathrm{As}_{\mathrm{i}}$ during metabolism in mammals that differ from alkylation in diester where arsenic is directly (and not through the oxygen atom) bonded to carbon atom. 


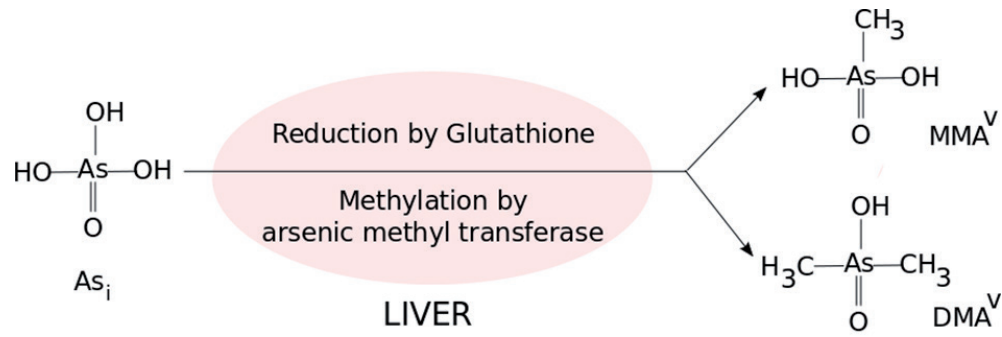

Excretory Products

Fig. 1. A general outline depicting mechanism of arsenate metabolism in mammals: MMA - monomethyl arsonic acid, DMA - dimethyl arsenic acid

\section{Methods}

Hydrolysis pathways for $\mathrm{As}_{\mathrm{i}}$ diester are well documented in the literature $[4,12]$. The associative pathway was claimed to be dominated over dissociative pathway [4]. This pathway follows $\mathrm{S}_{\mathrm{N}} 2$ mechanism, where the attack of water nucleophile on ester results in a reaction intermediate having a pentacoordinated centre with trigonal bipyramidal geometry. Further internal proton transfer leads to the breaking of As-O bond carrying the alkyl substituents.

To see the effect of alkyl substituent on hydrolysis rate of both As-O- and As-C-bond-based compounds, proto- types of chemical species in Fig. 3 were modelled.

PBE1PBE functional from DFT (Density Functional Theory) was used for the quantum chemical calculation in this work because it was recommend after benchmarking of DFT functionals for the hydrolysis of phosphodiester bonds [13]. 6-31G+ $(\mathrm{d}, \mathrm{p})$ basis set was selected for the calculation of hydrolysis rate constant. Polar solvent ( $\varepsilon=78.4$, water $)$ was employed with the Polarizable Continuum Model (PCM) using the integral equation formalism variant (IEFPCM) [14]. Since

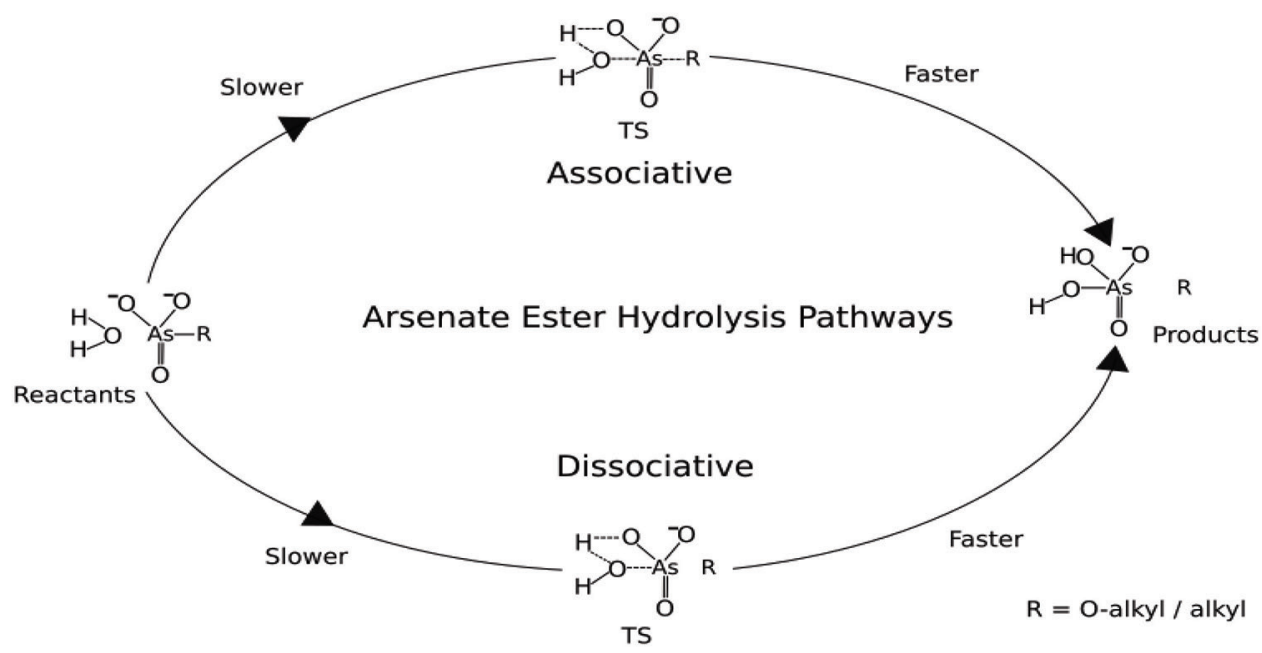

Fig. 2. Reaction pathways for hydrolysis of arsenate ester (TS - Transition State) 
we already described that the hydrolysis of $\mathrm{As}_{\mathrm{i}}$ follows $\mathrm{S}_{\mathrm{N}} 2$ mechanism where rate determining step is the attack of nucleophile, we modelled structures for reactants and TS only (see Fig. 2) for the determination of rate constant of hydrolysis reaction. Both optimization and frequency calculation of reactants" structures were performed by using PBE1PBE/6-31G+ $(d, p)$. Transition state structure was modelled first by using lower methods like hf (Hartree-Fock) with less computationally demanding gaussian basis set 3-21G with redundant internal coordinates geometry where we applied bond constrained on one proton of water molecule, which tunnel between negatively charged oxygen atom of ester and oxygen atom of water. Hessian displays negative eigenvalues, which verify the nature of a transition state that has been optimized, and shows the correct vibration of proton along a bond vector where we applied constrained (see Fig. 4)<smiles>C[As](C)(C)C(=O)O</smiles>

Arsenobetaine

(A)<smiles>C[As](C)(C)CCO</smiles>

Arsenocholine

(B)<smiles>C[As](C)(C)(C)c1ccccc1</smiles>

Arsenosugar

(C)

(i) As-C Bond Based Compounds<smiles>O=[As]([O-])([O-])O</smiles><smiles>[R]O[Sb]([R])(=O)([O-])[O-]</smiles>

Arsenate $\left(A s_{i}\right)$ Alkyl-O-Arsenate Ester (D)

(E)

(ii) As-O Bond Based Compounds

Fig. 3. As-C- and As-O-bond-based arsenic compounds further optimization of TS geometry, followed by frequency calculation by using ultrafine grid and PBE1PBE DFT method with 6-31G+ $(\mathrm{d}, \mathrm{p})$ basis set.

Aside from display of negative vibrational frequency, it is also necessary to identify the minima connected through the transition state. This latter part is performed through the intrinsic reaction coordinate (IRC), defined as the minimum energy reaction pathway in mass-weighted cartesian coordinates between the transition state of a reaction and its reactants and products [15]. IRC is basically a path that the molecule takes while moving down the product and reactant valleys with zero kinetic energy [15]. We calculate IRC with maximum 50 steps on both side with each step size of 0.0750 bohr (see Fig. 5).

The key equation for calculating reaction rates is

$$
k(298, H)=\frac{k_{B} T}{h c} e^{-\frac{\Delta G^{o}}{R T}} .
$$

We use $c^{0}=1$ for the concentration. Because of the final geometry, cartesian force constants and electronic energy are independent of the masses of the atoms, and only the vibrational analysis is massdependent [16].

The first step in calculating the rates of these reactions is to compute the free energy of activation, $\Delta G^{\circ}(H)$ of reaction at $298 \mathrm{~K}$, which is calculated by using Eq. 1:

$$
\begin{gathered}
\Delta G^{o}(298 K)= \\
=\sum\left(E_{o}+G_{\text {corr }}\right)_{\text {products }}- \\
-\sum\left(E_{o}+G_{\text {corr }}\right)_{\text {reactants }},
\end{gathered}
$$

where $\sum\left(E_{o}+G_{\text {corr }}\right)_{\text {products }}, \sum\left(E_{o}+G_{\text {corr }}\right)_{\text {reactants }}$ is sum of electronic and thermal free energies for products and reactants, respectively. 


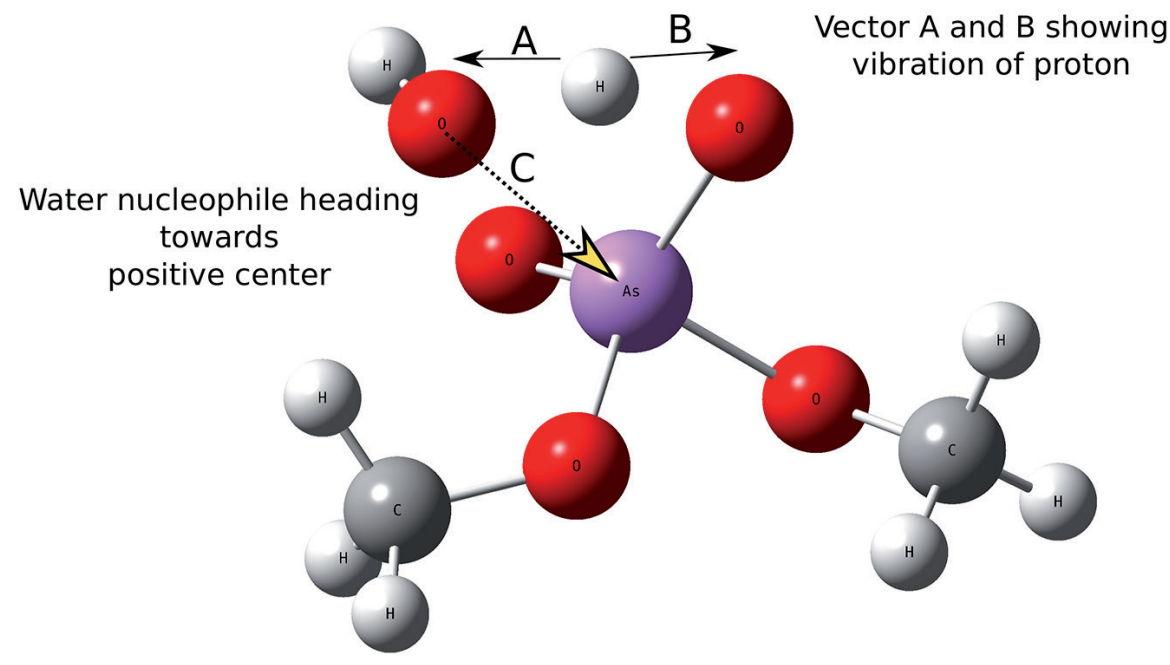

TS (Transition State) structure geometry of dimethyl arsenate optimized by using PBE1PBE/6-31G+(d,p)

Fig. 4. Bond constrains, applied along bond vector A, B and C in transition state structure geometry optimization of dimethylarsenate

Total Energy along IRC

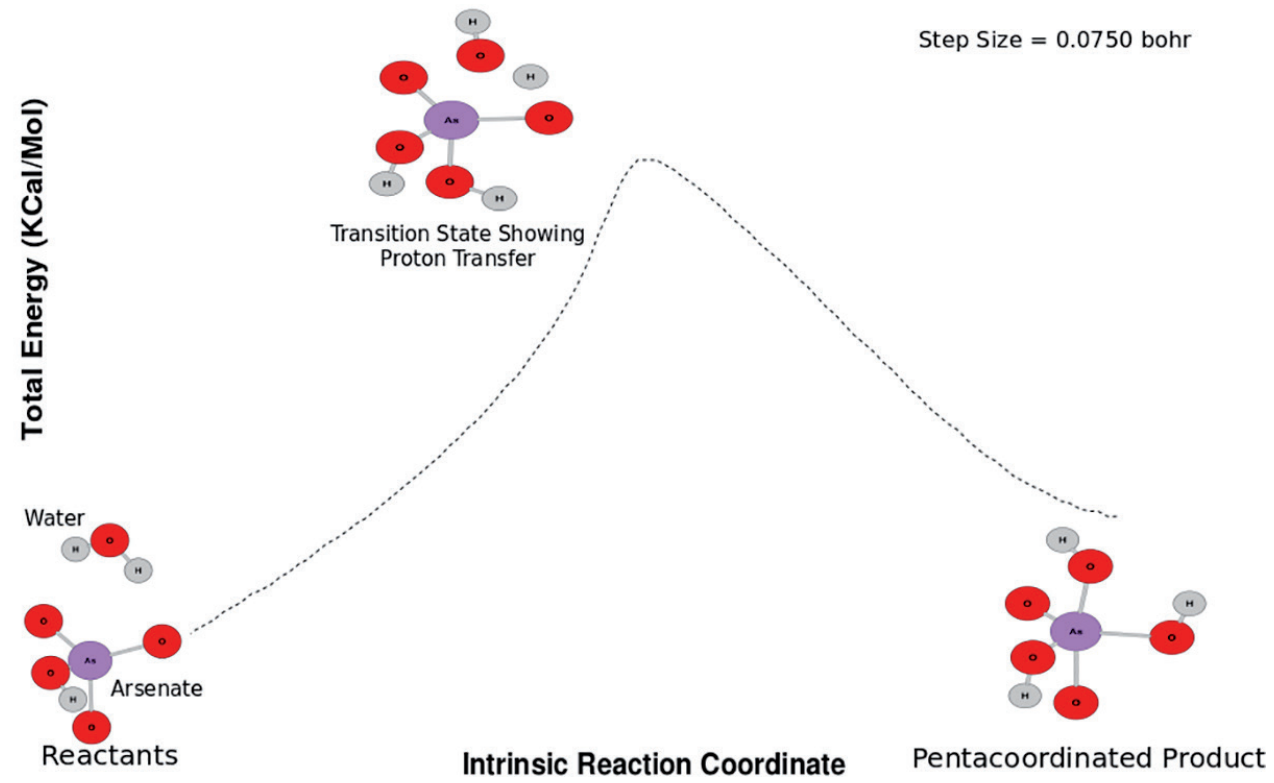

Fig. 5. Intrinsic reaction coordinates pathway for the rate-determining step in hydrolysis of arsenate with 50 steps on each side and step size of $0.0750 \mathrm{bohr}$ 


\section{Results and discussion}

Hydrolysis rate for both As-O- and AsC-bond-based compounds summarized in tables 2 and 3.

We also calculated the hydrolysis rate of alkyl-O-phosphate diester. On average, it was found to be $\sim 10^{-18} \mathrm{sec}^{-1}$, whereas for alkyl-O-arsenate diester it was $\sim 10^{-4} \mathrm{sec}^{-1}$. It is clear that arsenate diester is less stable as compared to phosphate diester. This is because As have higher metallic character than $\mathrm{P}$ in diester and that is why it is a stronger site for a nucleophilic attack as compared to P. In Fig. 6 we provide ESP (Electrostatic potential) charges for arsenate and phosphate in their respective diester. We use ESP charges in place of conventional Mulliken charges because

Hydrolysis Rate for As-O-bond-based compounds

\begin{tabular}{c|c|c}
\hline № & Arsenic Compounds & Rate of Hydrolysis $\left(\mathrm{in} \mathrm{sec}^{-1}\right)$ \\
\hline 1 & Dimethyl-O-Arsenate & $2 \cdot 10^{-4}$ \\
\hline 2 & Diethyl-O-Arsenate & $6 \cdot 10^{-4}$ \\
\hline 3 & Dipropyl-O-Arsenate & $1 \cdot 10^{-2}$
\end{tabular}

Table 3

Hydrolysis Rate for As-C-bond-based compounds

\begin{tabular}{c|c|c}
\hline № & Arsenic Compounds & Rate of Hydrolysis $\left({\left.\text { in } \mathrm{sec}^{-1}\right)}^{-1}\right.$ \\
\hline 1 & Arsenate & $8.0 \cdot 10^{-2}$ \\
\hline 2 & Monomethyl-Arsenate & $4.49 \cdot 10^{-5}$ \\
\hline 3 & Dimethyl-Arsenate & $1.18 \cdot 10^{-6}$ \\
\hline 4 & Trimethyl-Arsenate & $6.0 \cdot 10^{-7}$
\end{tabular}

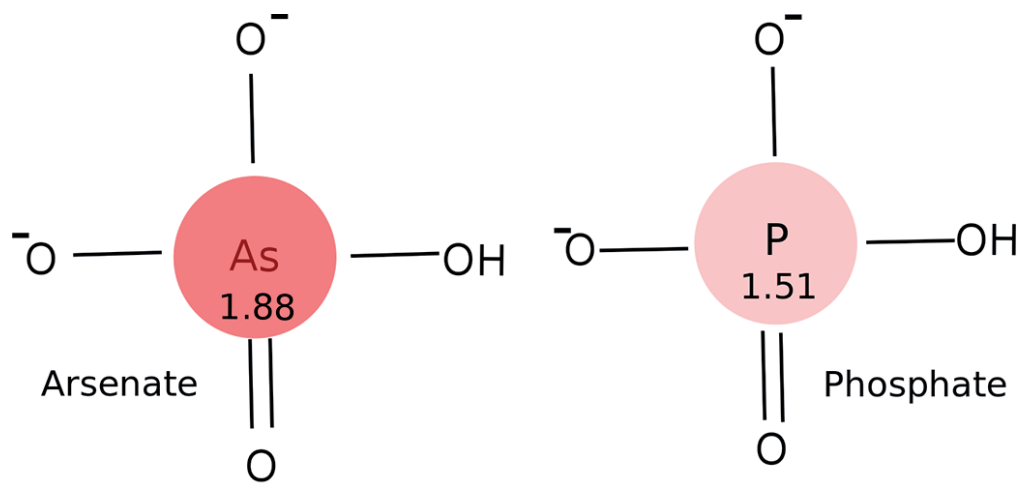

\section{ESP Charges (Scaled by colour intensity also) on Central Atom of Both Ester calculated by using MP2/aug-cc-pvtz}

Fig. 6. ESP (Electrostatic Potential) charges on central atom of diester of Arsenic and Phosphorous. Arsenic atom is more positively charged in its diester as compared with P. Polarizable Continuum Model (PCM) using the integral equation formalism variant (IEFPCM) was used to mimic effect of solvent $(\varepsilon=78.4$, water). Atomic charge is given in units of $\mathrm{e}$ 
they are much less dependent on the choice of basis set [17].

About 10 to 100 times fall in hydrolysis rate of As-C-bond-based compounds as compared to As-O-bond-based compounds was observed. This fall is due to the decrease in positive charge on central As atom (1.54e in case of dimethyl) because of the direct bonding of alkyl substituents to As, which are potent electron donating groups. Now, because As in As-C-bondbased compounds has lower positive charge as compared with charge on As in AsO-bond-based compounds, attack of nu- cleophilic water is less favoured over As in As-C compounds compared to As-O compounds. Our findings directly support the proposed mechanisms for the metabolism of arsenate in mammals [5] because arsenate needs to be stabilized first, then, to support excretion of methylated arsenic products by highly aqueous excretory organs, some polar groups must be attached, like carboxylic acid, hydroxyl, etc. After that, arsenate is fully metabolized and ready to excrete in form of becomes organoarsenicals (see A, B, and C in Fig. 3).

\section{Conclusions}

In our study we found that $\mathrm{As}_{\mathrm{i}}$ diester is highly prone to hydrolysis under physiological conditions as compared with $\mathrm{P}_{\mathrm{i}}$ diester, whereas organoarsenicals products are formed to protect $\mathrm{As}_{\mathrm{i}}$ from hydrolysis, otherwise it would be converted further to toxic $A s^{\mathrm{III}}$ (arsnite). Hence, methylation followed by attachment of a polar group to arsenate is a way to excrete out $\mathrm{As}_{\mathrm{i}}$ from body as organoarsenicals like arsenosugar, arsenobetaine, arsenocholine etc. Our work could help to understand the arsenic metabolic pathway inside living organisms. Same kind of approach could be useful for studying the mechanism of arsenite $\left(A s^{\text {III }}\right)$ toxicity. It was reported that As in arsenite is a potent bonding partner for sulphur by breaking disulfide linkages in proteins, which would results in dysfunction of that protein. DFT method (PBE1PBE) and basis set $(6-31 \mathrm{G}+(\mathrm{d}, \mathrm{p}))$ tested by our method would be helpful to study reaction mechanism between $A s^{I I I}$ in arsenite and $\mathrm{S}$ atom in protein, because both $\mathrm{S}$ and $\mathrm{O}$ belong to the same group and we successfully modelled the reaction between $\mathrm{O}$ and $\mathrm{As}^{\mathrm{V}}$ by using $\mathrm{PBE} 1 \mathrm{PBE} / 6-31 \mathrm{G}+(\mathrm{d}, \mathrm{p})$.

\section{References}

1. Cullen WR, Reimer KJ. Arsenic speciation in the environment. Chem Rev. 1989;89(4):713-64. DOI:10.1021/cr00094a002.

2. Kenney LJ, Kaplan JH. Arsenate substitutes for phosphate in the human red cell sodium pump and anion exchanger. J Biol Chem. 1988;263(17):7954-60.

3. Westheimer FH. Why nature chose phosphates. Science. 1987;235(4793):1173-8. DOI:10.1126/science.2434996.

4. Baer CD, Edwards JO, Rieger PH. Kinetics of the hydrolysis of arsenate (V) triesters. Inorg Chem. 1981;20(3):905-7.

5. Rehman K, Naranmandura H. Arsenic metabolism and thioarsenicals. Metallomics. 2012;4(9):881-92. DOI:10.1039/C2MT00181K. 
6. Lagunas R, Pestana D, Diez-Masa JC. Arsenic mononucleotides. Separation by highperformance liquid chromatography and identification with myokinase and adenylate deaminase. Biochemistry. 1984;23(5):955-60. DOI:10.1021/bi00300a024.

7. Adams SR, Sparkes MJ, Dixon HBF. The arsonomethyl analogue of adenosine 5'-phosphate. An uncoupler of adenylate kinase. Biochem J. 1984;221(3):829-36. DOI:10.1042/bj2210829.

8. Avron M, Jagendorf AT. Evidence concerning the mechanism of adenosine triphosphate formation by spinach chloroplasts. J Biol Chem. 1959;234(4):967-72.

9. Gresser MJ. ADP-arsenate. Formation by submitochondrial particles under phosphorylating conditions. J Biol Chem. 1981;256(12):5981-3.

10. Kline PC, Schramm VL. Purine nucleoside phosphorylase. Catalytic mechanism and transition-state analysis of the arsenolysis reaction. Biochemistry. 1993;32(48):13212-9. DOI:10.1021/bi00211a033.

11. Mládek A, Šponer J, Sumpter BG, Fuentes-Cabrera M, Šponer JE. Theoretical modeling on the kinetics of the arsenate-ester hydrolysis: implications to the stability of As-DNA. Phys Chem Chem Phys. 2011;13(23):10869-71. DOI:10.1039/C1CP20423H.

12. Schroeder GK, Lad C, Wyman P, Williams NH, Wolfenden R. The time required for water attack at the phosphorus atom of simple phosphodiesters and of DNA. Proc Natl Acad Sci USA. 2006;103(11):4052-5. DOI:10.1073/pnas.0510879103.

13. Ribeiro AJ, Ramos MJ, Fernandes PA. Benchmarking of DFT functionals for the hydrolysis of phosphodiester bonds. J Chem Theory Comput. 2010;6(8):2281-92. DOI:10.1021/ct900649e.

14. Miertuš S, Scrocco E, Tomasi J. Electrostatic Interaction of a Solute with a Continuum. A Direct Utilization of ab initio Molecular Potentials for the Prevision of Solvent Effects. Chem Phys. 1981;55:117-29. DOI:10.1016/0301-0104(81)85090-2.

15. Fukui K. The path of chemical reactions-the IRC approach. Acc Chem Res. 1981;14(12):363-8. DOI:10.1021/ar00072a001.

16. Ochterski JW. Thermochemistry in Gaussian [Internet]. c2000 [cited 2018 June 14]. Available from: http://gaussian.com/thermo/.

17. Martin F, Zipse H. Charge distribution in the water molecule - a comparison of methods. J Comput Chem. 2005;26(1):97-105. DOI:10.1002/jcc.20157. 